M. Yoshiyama ${ }^{1}$, F.R. Tay ${ }^{2}$, J. Doi ${ }^{1}$, Y. Nishitani ${ }^{1}$, T. Yamadal', K. Itou ${ }^{1}$, R.M. Carvalho ${ }^{3}$, M. Nakajima ${ }^{4}$, and D.H. Pashley ${ }^{5 *}$

${ }^{1}$ Department of Operative Dentistry, Okayama University Graduate School of Medicine and Dentistry, 2-5-1, Shikatacho, Okayama 700-8525, Japan; ${ }^{2}$ Department of Conservative Dentistry, Faculty of Dentistry, The University of Hong Kong, 34 Hospital Road, Hong Kong, China;

${ }^{3}$ Department of Operative Dentistry, Endodontics and Dental Materials, Bauru School of Dentistry, University of São Paulo, Bauru, São Paulo, 17012-901, Brazil; ${ }^{4}$ Department of Operative Dentistry, Tokyo Medical and Dental University, Tokyo, Japan; and ${ }^{5}$ Department of Oral Biology, Medical College of Georgia, Augusta, Georgia 30912-1129, USA;

*corresponding author, dpashley@mail.mcg.edu

J Dent Res 81(8):556-560, 2002

\begin{abstract}
Carious dentin is partially demineralized and contains mineral crystals in the tubules. This may permit the deeper etching of intertubular dentin but prevent resin tag formation during bonding. We hypothesize that resin adhesives will produce lower bond strengths to caries-infected and caries-affected dentin compared with normal dentin. We tested this by measuring the microtensile bond strength of a total-etch adhesive and an experimental self-etching adhesive (ABF) to caries-infected, caries-affected, and sound dentin and by correlating those results with ultrastructural observations. The bond strengths of both adhesives to sound dentin were significantly $(p<0.05)$ higher than those to cariesaffected dentin, which, in turn were significantly ( $p$ $<0.05$ ) higher than those to caries-infected dentin. For both adhesives, hybrid layers in caries-affected dentin were thicker but more porous than those in sound dentin. The lower bond strengths may be due to the lower tensile strength of caries-affected dentin. Clinically, this may not be a problem, since such lesions are normally surrounded by normal dentin or enamel.
\end{abstract}

KEY WORDS: self-etch, total-etch, caries-affected dentin, caries-infected dentin, microtensile bond strength.

Received January 2, 2002; Last revision April 19, 2002; Accepted May 28, 2002

A supplemental appendix to this article is published electronically only at http://www.dentalresearch.org

\title{
Bonding of Self-etch and Total-etch Adhesives to Carious Dentin
}

\section{INTRODUCTION}

n contemporary minimally invasive restorative dentistry, the primary aim in the excavation of carious dentin is to remove only the outer layer of highly infected, denatured caries-infected dentin (Massler, 1967). This facilitates the preservation of the inner layer of intact, bacteria-free remineralizable cariesaffected dentin (Wei et al., 1968) and prevents disease progression. Conversely, recent studies showed that the application of adhesive-sealed composite restorations to irreversibly infected dentin did not affect the clinical performance of these restorations (Briley et al., 1997; Ribeiro et al., 1999).

With the advent of contemporary hydrophilic self-etch and total-etch adhesives, it may be possible to bond to and seal vital caries-affected and cariesinfected dentin and isolate residual bacteria from any fermentable carbohydrates that are present in the oral fluids or nutrients that are derived from the pulp. This may permit dentinogenesis to isolate residual bacteria even further, causing them to become dormant (Bjørndal and Darvann, 1999). The clinical consequence of leaving residual bacteria underneath bonded restorations is still a subject of considerable debate. Newly developed techniques involving polymerase chainreaction amplification of bacterial surface protein antigens showed that conventional culture techniques could underestimate the quantity of viable bacteria beneath restorations (Allaker et al., 1998). Remaining viable bacteria may release antigens into the pulp and induce cytokine reactions, evolving to chronic pulpal inflammation (Hahn et al., 2000).

The diagnosis and removal of active caries are therefore crucial (Weerheijm and Groen, 1999), since the inherent subjectivity in detection of the excavation boundary can result in clinically significant differences in the quality and quantity of dentin removed by different operators (Banerjee et al., 2000). Thus, it is possible that clinicians are bonding to a substrate that is composed of sound, caries-affected, and caries-infected dentin in different parts of the same cavity.

The objectives of this study were to examine the microtensile bond strength and interfacial ultrastructure on bonding of a self-etch adhesive and a total-etch adhesive to carious dentin. The hypotheses tested were that: (1) dentin adhesives bond equally well to sound, caries-affected, and cariesinfected dentin; and (2) there is no difference between a self-etch and a totaletch adhesive in bonding to these respective dentin substrates.

\section{MATERIALS \& METHODS}

\section{Selection of Bonding Substrates}

Sixteen extracted human molars with coronal dentin caries were used in this study. The teeth were collected after the patients' informed consent was obtained 
under a protocol reviewed and approved by the institutional review board of the Medical College of Georgia. They were stored in $0.9 \% \mathrm{NaCl}$ containing $0.05 \%$ sodium azide at $4^{\circ} \mathrm{C}$, and used within one month following extraction. The occlusal enamel and superficial dentin were removed by means of a slow-speed saw (Isomet, Buehler Ltd., Lake Bluff, IL, USA) under water lubrication, exposing a flat surface of middle to deep dentin where the caries lesion was surrounded by normal dentin (Appendix Fig. A; www.dentalresearch.org). The entire flat surface was flooded with Caries Detector solution to stain the lesion (Kuraray Medical Inc., Tokyo, Japan). Further reduction was performed with 600 -grit $\mathrm{SiC}$ paper under running water according to the combined criteria of: hardness to a sharp excavator, visual examination, and staining with Caries Detector solution. The relatively soft, dark-red-stained dentin was classified as caries-infected dentin, while the discolored, harder dentin that stained pink was classified as cariesaffected dentin. The surrounding, yellow, hard dentin was classified as normal dentin.

\section{Experimental Design}

An experimental self-etch adhesive with antibacterial (Imazato et al., 1998) properties (ABF system, Kuraray) and a commercially available total-etch, moist-bonding adhesive (Single Bond, 3M-ESPE) were used in this study (Appendix Table; www.dentalresearch.org). The experimental self-etching primer system contains an antibacterial monomer, 12-methacryloyloxydodecylpyridinium bromide (MDPB), that is bactericidal before polymerization and bacteristatic after polymerization (Imazato et al., 1998) and has been suggested to be useful for eliminating residual bacteria in carious dentin.

Eight teeth (4 with caries-affected dentin and 4 with cariesinfected dentin) were treated with the ABF primer for $20 \mathrm{sec}$ under agitation and gently air-dried. The ABF adhesive was then applied, gently air-thinned, and light-cured for $20 \mathrm{sec}$. Another 8 teeth (4 with caries-affected dentin and 4 with caries-infected dentin) were etched with $35 \%$ phosphoric acid gel for $15 \mathrm{sec}$ and rinsed for $15 \mathrm{sec}$, leaving a visibly moist surface. Two consecutive coats of Single Bond adhesive were applied and light-cured for $10 \mathrm{sec}$. Composite build-up was performed with Clearfil AP-X (Kuraray) in $31.5-\mathrm{mm}$-thick increments. The teeth were then stored in water at $37^{\circ} \mathrm{C}$ for $24 \mathrm{hrs}$.

Each tooth was vertically sectioned into 5 or 60.8 -mm-thick serial slabs by means of an Isomet saw under water lubrication. We examined these under a dissecting microscope to separate slabs containing resin-bonded normal dentin from those that contained caries-affected or caries-infected dentin. This yielded about 3 slabs of bonded normal dentin, and 3 slabs of bonded caries-affected or cariesinfected dentin per tooth. The slabs were hand-trimmed into dumbbellshaped specimens according to the technique for the microtensile bond test reported by Sano et al. (1994), with the smallest dimension at the bonded interface representing the bonded tissue of interest.

\section{Microtensile Bond Strength Evaluation}

From 7 to 9 trimmed specimens from each group were used for bond strength evaluation. Specimens were stressed to failure under tension by means of a universal testing machine (Model 4440; Instron Inc., Canton, MA, USA) at a crosshead speed of $1 \mathrm{~mm}$ per min. The results were analyzed by a two-way analysis of variance (adhesives vs. dentin type), and multiple comparisons were done by Tukey's test at $\alpha=0.05$.

\section{Transmission Electron Microscopy}

The remaining 3 to 5 slabs of resin-bonded dentin from each group were cut into $1 \times 0.8-\mathrm{mm}$ sticks and prepared according to the
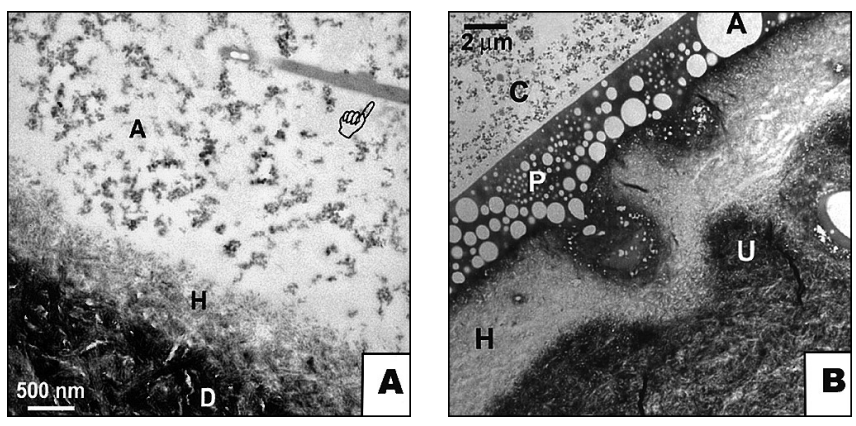

Figure 1. Transmission electron micrographs (TEM) of undemineralized specimens. (A) Unstained section of the resin-dentin interface in a specimen bonded by means of the self-etch ABF system. A 1- $\mu$ m-thick hybrid layer $(\mathrm{H})$ could be seen within the partially demineralized dentin. Sodium fluoride crystals (pointer) were present in the filled adhesive (A). D, undemineralized sound dentin. (B) Stained section of the resin-dentin interface in a specimen bonded with the total-etch adhesive Single Bond. A thick layer of the polyalkenoic acid copolymer (P) component of the adhesive (A) was formed on top of a 5-im-thick hybrid layer. C, resin composite; U, undemineralized sound dentin.

Table. Microtensile Bond Strengths of a Self-etch Adhesive and a Totaletch Adhesive to Sound, Caries-affected, and Caries-infected Dentin

\begin{tabular}{lll}
\hline Dentin Substrate & Self-etch Adhesive $^{a}$ & Total-etch Adhesive $^{b}$ \\
\hline Sound dentin & $44.9 \pm 14.6(7)^{1}$ & $50.9 \pm 3.9(7)^{1}$ \\
Caries-affected dentin & $25.3 \pm 5.0(7)^{2}$ & $28.8 \pm 6.3(7)^{2}$ \\
Caries-infected dentin & $15.2 \pm 3.6(7)^{3}$ & $19.4 \pm 4.4(7)^{3}$ \\
\hline
\end{tabular}

a Values are mean \pm standard deviation (number of specimens) bond strengths in megaPascals.

${ }^{b}$ Groups identified with the same superscript numbers are not significantly different $(P>0.05)$.

transmission electron microscopy protocol described by Tay et al. (1999). Undemineralized, 90-nm-thick ultrathin sections of the epoxy-resin-embedded bonded specimens containing the bonded dentin substrate of interest were examined either unstained, or double-stained with uranyl acetate and Reynold's lead citrate, with the use of a transmission electron microscope (Philips EM208S, Eindhoven, The Netherlands) operating at $80 \mathrm{kV}$.

\section{RESULTS}

Microtensile bond strength results are shown in the Table. Analysis of variance indicated that there were significant differences $(p<0.001)$ among dentin types, but not between adhesives $(p=0.35)$. There was no significant interaction between the two factors $(\mathrm{p}=0.29)$. Bond strengths to sound dentin were significantly higher than those to caries-affected dentin, which, in turn, were significantly higher than those to caries-infected dentin $(\mathrm{p}<0.05)$.

Transmission electron microscopy of resin-dentin interfaces in sound dentin showed that 0.5 - to $1-\mu \mathrm{m}$-thick hybrid layers were produced by the self-etch ABF system (Fig. 1A) and 5- $\mu$ mthick hybrid layers were created when the total-etch Single Bond adhesive was used (Fig. 1B). For both adhesives, hybrid layers in caries-affected dentin were much thicker than those observed in sound dentin, and their dentinal tubules were often obliterated with heavy mineral deposits. Although hybrid layers were from 3 

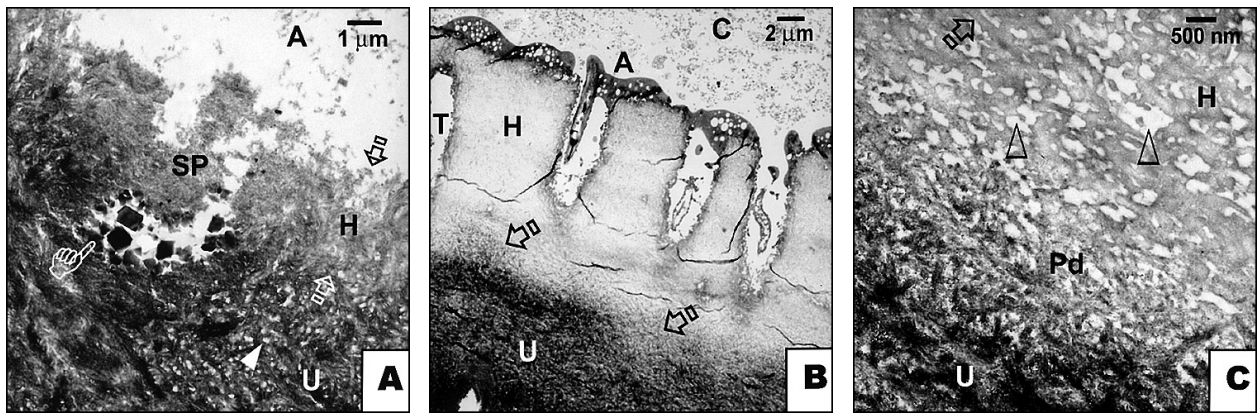

Figure 2. TEM of undemineralized specimens of resin-bonded caries-affected dentin. (A) Stained TEM of undemineralized specimens following the application of the self-etch $A B F$ system to caries-affected dentin. The hybrid layer ( $\mathrm{H}$; between arrows) was about $3 \mu \mathrm{m}$ thick, and the underlying undemineralized dentin (U) was highly porous (arrowhead). The dentinal tubule was covered with a smear plug (SP) and was partially obliterated with large caries crystals (pointer). A, filled adhesive. (B) Stained section of the totaletch Single Bond adhesive bonded to caries-affected dentin. A hybrid layer (H) between 15 and $19 \mu \mathrm{m}$ thick could be seen, with a partially demineralized zone (open arrows) above the undemineralized cariesaffected dentin (U). T, dentinal tubule. C, composite. (C) Higher magnification of the basal part of the unusually thick hybrid layer $(\mathrm{H})$ shown in Fig. 2A. Banded collagen fibrils (open arrow) were separated by unusually wide and porous interfibrillar spaces (open arrowheads). A partially demineralized zone (Pd) was present along the demineralization front. This zone was not seen in phosphoric-acid-etched sound dentin (Fig. 1B). U, undemineralized caries-affected dentin.

to $8 \mu \mathrm{m}$ thick for the self-etch system (Fig. 2A), and between 15 and $19 \mu \mathrm{m}$ thick for the total-etch system (Fig. 2B), porous zones of carious-affected dentin could be seen either beneath the hybrid layer in the self-etch adhesive (Fig. 2A) or along the base of the hybrid layer in the total-etch adhesive (Fig. 2C).

When thin layers of caries-infected dentin were encountered, the self-etch adhesive could form hybrid layers that incorporated the superficial caries-infected dentin and part of the underlying caries-affected dentin (Fig. 3A). However, when thick layers of caries-infected dentin were present, the self-etch adhesive was unable to etch and infiltrate beyond this infected, grossly denatured layer. The dentinal tubules remained incompletely sealed with resin (Fig. 3B). In areas that were about $100 \mu \mathrm{m}$ beneath the bonded interface, we observed isolated regions containing large bacteriainfected zones with complete destruction of both intertubular and peritubular dentin (Frank et al., 1989). The bacteria in these zones exhibited intact cell walls and contained electron-lucent, glycogen-like intracellular polysaccharide granules (Hamilton, 1976) in their cytoplasm (Fig. 3C).

For the total-etch adhesive, loose dentin chips were often trapped within the adhesive. Numerous bacteria could be seen in the tubules (Fig. 3D). Bacteria along the surface of the cariesinfected dentin were often trapped within the polyalkenoic acid copolymer component of the adhesive. Most of them exhibited intact cell walls and contained carbohydrate granules in their cytoplasm. Some of these bacteria were in the process of cell division before laboratory fixation (Fig. 3C).

\section{DISCUSSION}

Since both adhesives exhibited higher tensile bond strengths to sound dentin than to caries-affected or caries-infected dentin, we must reject the first null hypothesis. However, there was no difference between the self-etch and the total-etch adhesive in bonding to these respective dentin substrates. Thus, we must accept the second null hypothesis.

There are several potential problems that may affect bonding and sealing efficacy when hydrophilic self-etch and
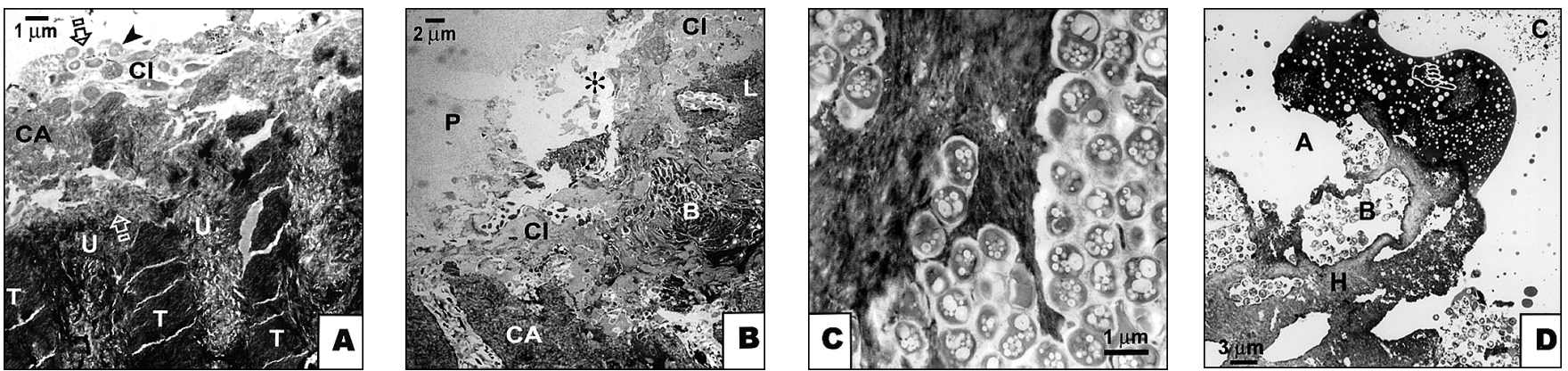

Figure 3. TEM of undemineralized specimens, showing the variability in bonding of a self-etch and a total-etch adhesive to caries-infected dentin. (A) Stained section of a specimen bonded with the self-etch ABF system. The hybrid layer region (between open arrows) consisted of a superficial layer of carious-infected dentin (Cl) that contained bacteria (arrowhead) mixed with some caries-affected dentin (CA). The underlying caries-affected dentin (U) was highly porous. The dentinal tubules (T) were completely obliterated with minerals. (B) Stained section of a specimen bonded with the ABF system, showing a thick layer of caries-infected dentin that contained loose dentin chips (L) and bacteria (B). The extent of the hybrid layer could not be clearly discerned. Caries-infected dentin did not form a hybrid layer in the underlying caries-affected dentin (CA). A gap (asterisk) was present between the unfilled primer component of the adhesive $(P)$ and the surface of the caries-infected dentin. This gap was subsequently filled with the more electron-lucent epoxy resin that was used for laboratory specimen preparation. (C) High magnification of stained section of an ABF specimen showing caries-affected dentin that was about $100 \mu \mathrm{m}$ beneath the bonded interface. Destruction of the intertubular and peritubular dentin resulted in the confluence of tubules that were filled by micro-organisms. Glycogen-like intracellular polysaccharide granules could be identified within the cytoplasm of the bacteria, some of which were dividing. (D) Stained section of the superficial part of the hybrid layer (H) in a cariesinfected dentin specimen bonded with the total-etch, Single Bond adhesive. A loose dentin fragment (pointer) was trapped within the copolymer (P) of the adhesive (A). B, bacteria within dentinal tubules; C, composite. 
total-etch adhesives are used on caries-affected and cariesinfected dentin. Caries-affected dentin is softer than normal dentin (Fusayama et al., 1966; Ogawa et al., 1983; Marshall et al., 2001a) because it is partially demineralized. Carious intertubular dentin exhibits a higher degree of porosity than sound intertubular dentin, due to the loss of mineral. Our ultrastructural results agreed with previous studies that hybrid layers in caries-affected dentin were thicker than those in sound dentin (Nakajima et al., 1995), suggesting easier diffusion of acidic conditioners and adhesive monomers, due to increased porosity in the intertubular dentin. Conversely, resin infiltration into dentinal tubules was severely hampered by the presence of acid-resistant mineral casts within dentin tubules of both caries-affected and caries-infected dentin (Marshall et al., 2001b). This can lower resin retention, particularly when the relatively mild-acting self-etching primers are used. In parallel experiments, we measured the Knoop hardness and ultimate tensile strength of normal and caries-affected dentin. Cariesaffected dentin was softer and weaker than normal dentin (Appendix Fig. A; www.dentalresearch.org). Many specimens of resin-bonded caries-affected dentin failed cohesively in dentin, presumably because it was weaker than the bonding resin. This did not occur in normal dentin, where the bonds failed adhesively. Thus, the lower tensile bond strength of the two tested adhesives to caries-affected and infected dentin compared with normal dentin is probably due to several factors: the lack of resin tag formation due to the presence of acid-resistant intratubular mineral deposits; and decreases in the modulus of elasticity (Marshall et al., 2001a,b) and the cohesive strength of such dentin (Appendix Fig. B, www.dentalresearch.org). We speculate that the unmeasurable Knoop hardness of caries-infected dentin is due to the nearcomplete loss of the mineral phase of dentin and to denaturation of its collagen matrix. The low Knoop hardness values in caries-infected dentin may reflect a smaller number of larger apatitic crystals that no longer fit properly into inter- and intrafibrillar spaces in a normal collagen matrix. To the extent that there is any chemical bonding between carboxylic or phosphate derivatives of methacrylates with the mineral phase, then fewer, larger crystals would offer less surface area for interaction. Hydrogen bonding between resins and collagen may contribute to bond strength in normal dentin and perhaps to caries-affected dentin if it has normal collagen, but it could not occur with the denatured matrix of caries-infected dentin.

The intrinsic weakness of caries-affected and caries-infected dentin may not be a clinical problem if there is normal dentin and/or enamel surrounding the excavated lesion that can provide high bond strengths with resin adhesives. This was probably responsible for the excellent 10-year results of clinical trials of resin-sealed caries lesions (Mertz-Fairhurst et al., 1998).

In conclusion, we do not advocate that these adhesives be bonded to clinically detectable soft, wet, carious dentin. However, the boundary between caries-affected and cariesinfected dentin is often not clear. Our results suggest that the resins can infiltrate into porous caries-affected dentin matrices and into thin zones of caries-infected dentin. Much more research is needed to determine the effectiveness of phosphoric acid gel (Jensen and Handelman, 1980) compared with antibacterial self-etching adhesive monomers in killing bacteria in dentin, the permeability of polymerized resins to water and fermentable sugars, whether monomers penetrate the cytoplasm of bacteria, and whether bacteria can degrade the resin. Until more information is available on these questions, clinicians are advised to remove as much caries-infected dentin as possible. Any thin region of residual caries-infected dentin may be sequestered by adhesive resins. The long-term benefits/risks of this remain to be determined.

\section{ACKNOWLEDGMENTS}

The adhesives used in this study were generously supported by Kuraray Medical Inc. and 3M-ESPE. The authors are grateful to Michelle Barnes for secretarial support. This work was supported, in part, by grant DE06427 from the NIDCR and grant number 300481/95-0 from CNPq, Brazil.

\section{REFERENCES}

Allaker RP, Seddon SV, Tredwin C, Lynch E (1998). Detection of Streptococcus mutans by PCR amplification of the spaP gene in teeth rendered caries free. $J$ Dent 26:443-445.

Banerjee A, Kidd EA, Watson TF (2000). In vitro evaluation of five alternative methods of carious dentine excavation. Caries Res 34:144-150.

Bjørndal L, Darvann T (1999). A light microscopic study of odontoblastic and non-odontoblastic cells involved in tertiary dentinogenesis in well-defined cavitated carious lesions. Caries Res 33:50-60.

Briley JB, Dove SB, Mertz-Fairhurst EJ, Hermesch CB (1997). Computer-assisted densitometric image analysis (CADIA) of previously sealed carious teeth: a pilot study. Oper Dent 22:105-114.

Frank RM, Steuer P, Hemmerle J (1989). Ultrastructural study on human root caries. Caries Res 23:209-217.

Fusayama T, Okuse K, Hosoda H (1966). Relationship between hardness, discoloration and microbial invasion in carious dentin. $J$ Dent Res 45:1033-1046.

Hahn CL, Best AM, Tew JG (2000). Cytokine induction by Streptococcus mutans and pulpal pathogenesis. Infect Immun 68:6785-6789.

Hamilton IR (1976). Intracellular polysaccharide synthesis by cariogenic microorganisms. In: Proceedings: microbial aspects of dental caries. Stiles HM, Loesche WJ, O’Brien TL, editors. Spec suppl, Microbiol abstr. Vol. 3. Washington, DC:Information Retrieval, Inc., pp. 683-701.

Imazato S, Ehara A, Torii M, Ebisu S (1998). Antibacterial activity of dentine primer containing MDPB after curing. J Dent 26:267-271.

Jensen OE, Handelman SL (1980). Effect of an autopolymerizing sealant on viability of microflora in occlusal dental caries. Scand $J$ Dent Res 88:382-388.

Marshall GW, Habelitz S, Gallagher R, Balooch M, Balooch G, Marshall SJ (2001a). Nanomechanical properties of hydrated carious human dentin. J Dent Res 80:1768-1771.

Marshall GW Jr, Chang YJ, Gansky SA, Marshall SJ (2001b). Demineralization of caries-affected transparent dentin by citric acid: an atomic force microscopy study. Dent Mater 17:45-52.

Massler M (1967). Changing concepts in the treatment of carious lesions. Br Dent J 123:547-548.

Mertz-Fairhurst EJ, Curtis JW Jr, Ergle JW, Rueggeberg FA, Adair SM (1998). Ultraconservative and cariostatic sealed restorations: results at year 10. J Am Dent Assoc 129:55-66.

Nakajima M, Sano H, Burrow MF, Tagami J, Yoshiyama J, Ebisu S, et al. (1995). Tensile bond strength and SEM evaluation of 
caries-affected dentin using dentin adhesives. $J$ Dent Res 74:1679-1688.

Ogawa K, Yamashita Y, Ichijo T, Fusayama T (1983). The ultrastructure and hardness of the transparent layer of human carious dentin. J Dent Res 67:7-10.

Ribeiro CC, Baratieri LN, Perdigão J, Baratieri NM, Ritter AV (1999).

A clinical, radiographic, and scanning electron microscopic evaluation of adhesive restorations on carious dentin in primary teeth. Quintessence Int 30:591-599.

Sano H, Shono T, Sonoda H, Takatsu T, Ciucchi B, Carvalho RM, et al. (1994). Relationship between surface area for adhesion and tensile bond strength-evaluation of a micro-tensile bond test. Dent Mater 10:236-240.

Tay FR, Moulding KM, Pashley DH (1999). Distribution of nanofillers from a simplified-step adhesive in acid-conditioned dentin. $J$ Adhes Dent 2:103-117.

Weerheijm KL, Groen HJ (1999). The residual caries dilemma. Community Dent Oral Epidemiol 27:436-441.

Wei SH, Kaqueller JC, Massler M (1968). Remineralization of carious dentin. J Dent Res 47:381-391. 